\title{
Inequality of opportunity in the land of opportunities, 1968-2001
}

\author{
Nicolas Pistolesi
}

Received: 21 May 2007 / Accepted: 9 July 2008

C Springer Science + Business Media, LLC 2008

\begin{abstract}
We measure inequality of opportunity for earnings acquisition in the U.S. between 1968 and 2001. Following recent theories of social justice, earnings determinants are divided into two parts: Circumstances, which are characteristics outside individual control and effort representing factors impacting earnings but under individuals' responsibility. Equality of opportunity requires that inequality of circumstances must be corrected while differences of effort must remain unaltered. Circumstances are represented by parental education and occupation, ethnic origin, place of birth and age. Effort is modeled with schooling choices and labour supply decisions. Using the PSID from 1968 to 2001, we provide two alternative assessments of inequality of opportunity using counterfactual distributions. The statistical framework is semi-parametric and builds on duration models. Finally, we conclude that inequality of opportunity represents between 20 and $43 \%$ of earnings inequality, but decreases all over the period reaching around $18 \%$ in 2001.
\end{abstract}

Keywords Equality of opportunity • Inequality • Income distribution • Semi-parametric estimator

\section{JEL Classification D31 • D63}

\section{Introduction}

Over the last 30 years, the U.S. has displayed a higher level of earnings inequality than most other western developed countries [28]. International comparisons of earnings inequality have mainly paid attention to changes in labour demand and supply, and to institutions ruling the labour market [20]. More recent studies [1] have

N. Pistolesi $(\varangle)$

TSE-GREMAQ, Université des sciences sociales de Toulouse,

21, allée de Brienne 31000 Toulouse, France

e-mail: nicolas.pistolesi@univ-tlse1.fr 
pointed out political and social institutional mechanisms. According to these authors, other noneconomic factors such as the political system, the size of the country and its history would account for part of the larger American earnings inequality.

An alternative view considers that across the two sides of the Atlantic the social perception of justice relies on different ethical values. Following that view, popular belief that effort and willingness are essential parts in the determination of social positions in the U.S. would conflict with a European conception for which inheritance of the past and luck play a larger role in shaping individual outcomes. ${ }^{1}$ Hence, the American Society would not consider that a large income redistribution would be necessary, while in Europe a different perception of the causes of inequality would advocate such policies.

With regard to these differences, correction of total inequality might not be the best definition of the goal of social justice in the U.S. A conception of justice introducing individual responsibility might be better at reflecting why redistributive policies are less developed in the U.S. compared to continental Europe. The distinction of factors generating interindividual income differences between on the one hand those resulting from individual responsibility, commonly called effort, and on the other hand those exogenous to individual choices, called circumstances, has been strongly supported over the last 20 years by philosophers on responsibility such as Dworkin [17], Arneson [3] or Roemer [34]. These authors have advocated that inequality that individuals can be held responsible for should not be corrected, while it is morally fair to aim at correcting inequality resulting from factors exogenous to individual choice.

In this paper we assess earnings inequality in the U.S. from 1968 to 2001 reflecting these theories of justice. In order to represent effort, we use earnings variation sources stemming from individual choices: human capital investment and labour supply decisions. These factors impact individual earnings but may at the same time be correlated with determinants exogenous to individual responsibility. To represent circumstances we use individual social background, since most authors would admit social background is an unfair source of inequality. We use the full Panel Study of Income Dynamics from 1968 to 2001 providing individual earnings, education, occupation, and labour supply behaviours over two generations. This description of social background is still partial. It remains remarkably detailed compared with what is available in other data sets. Given that information, we conclude that social background impacts schooling choices but relatively less labour supply decisions. Finally, over the period inequality of opportunity represents between $20 \%$ and $43 \%$ of earnings inequality depending on the inequality index chosen and has decreased reaching around $18 \%$ of total earnings inequality in 2001.

Several empirical analyses of inequality of opportunity have already been proposed. Dardanoni et al. [13], or Betts and Roemer [6] have focused on the U.S. in the nineties looking at the best policy to equalize opportunities for income across ethnic groups. Another interesting contribution provided by Bourguignon et al. [8] turns to the Brazilian case and decomposes the share of total observable inequality

\footnotetext{
${ }^{1}$ Alesina and La Ferrara [2] present a study on individual preferences for redistribution in the U.S. Alesina and Glaeser [1] review deeply the idea that Americans believe social mobility is important in their country, and that poor people have large opportunities for climbing the social ladder. While, Europeans perceive a lower social mobility in their country.
} 
due to inequality of opportunity. Moreover they develop a longitudinal perspective looking at the changes in Equality of Opportunity across cohorts. Finally, Checchi and Peragine [12] turn to the Italian case and propose a decomposition close to Bourguignon et al. [8] but on Italian data and with inequality indexes. In regards to these previous analyses, this article contributes in several respects to the literature. Firstly, we implement a longitudinal analysis over 33 years in the US. As outcome inequality has strongly increased over the period, it is interesting to know whether inequality of opportunity has surged or if the two inequality concepts provide different pictures of the American society. Providing an assessment of the change over time of inequality of opportunity is the first contribution of the paper. Secondly, this paper implements recent econometric techniques to estimate and simulate counterfactual earnings distributions due to Donald et al. [16]. The decomposition implemented here is inspired from Bourguignon et al. [8] contribution's but with an alternative econometric strategy. This new empirical approach is the second contribution of the paper. Thirdly, we develop a double perspective with two symmetric but different approaches focusing on the one hand on inequality due to the circumstances and on the other on inequalities due to effort. It provides some sensitivity analysis of the results. This double approach is the third contribution of the paper.

The next section develops our methodology and the statistical framework. Section 3 describes the PSID data. Results and their analysis are presented in Sections 4 and 5. Section 6 concludes.

\section{Measuring equality of opportunity: two approaches}

To measure equality of opportunity, the first theoretical contributions were Roemer [33] and Van de Gaer [35]. Dividing the population in different sets of individuals sharing the same circumstances Roemer proposed comparing the conditional income distributions, while Van de Gaer axiomatized comparing the conditional means. Their conditional approaches have been followed by several empirical analyses: Lefranc et al. [26], Dardanoni et al. [13], or Betts and Roemer [6]. In this paper we study the unconditional earnings distribution, as Bourguignon et al. [8] and Checchi and Peragine [12]. Our framework can be presented as follows: Let $x^{e}$ be effort, and $x^{c}$ circumstances. These are two univariate random variables. Earnings is a random variable $y$. The observed earnings density can be written:

$$
f_{y}(y)=\int_{x^{e}} \int_{x^{c}} f\left(y \mid x^{e}, x^{c}\right) h\left(x^{e}, x^{c}\right) d x^{e} d x^{c}
$$

With $h(\cdot, \cdot)$ a bivariate distribution of effort and circumstances. As Roemer [34] has argued convincingly, if individuals coming from more privileged circumstances can exert higher effort level, then to measure inequality of opportunity it is more relevant to assess relative effort differences. The density can then be written:

$$
f_{y}(y)=\int_{x^{e}} \int_{x^{c}} f\left(y \mid x^{e}, x^{c}\right) h_{e}\left(x^{e} \mid x^{c}\right) g\left(x^{c}\right) d x^{e} d x^{c}
$$

With $h_{e}(\cdot \mid)$ a conditional effort distribution and $g(\cdot)$ a marginal circumstances distribution. With this definition of effort, an individual exerts an higher (relative) effort if he is ranked higher in his conditional distribution. Hence, individuals from 
different circumstances but at the same conditional quantile have exerted the same effort. From Eq. 2 two different measures of inequality of opportunity can be implemented. The next section presents the first, Section 2.2 presents the second.

\subsection{The indirect approach: measuring inequality of effort}

A first definition states that there is equality of opportunity if and only if only effort differences generate earnings differences. Therefore, we can compare the observed distribution with a hypothetical distribution in which earnings inequality stems only from effort differences. To build that counterfactual distribution we simulate an earnings density in which individuals benefit from an identical set of circumstances but keep their observed conditional effort. To that purpose we proceed in two steps. In the first step, we simulate effort for each individual from an identical set of circumstances. In the second step, we simulate earnings conditional on the simulated effort and with the same set of circumstances.

Firstly, starting from Eq. 2 we estimate the conditional effort distribution $h_{e}\left(\cdot \mid x^{c}\right)$. In our modeling, it is a nonlinear function of the parameters, so $h_{e}\left(\cdot \mid x^{c}\right)=\theta_{1}\left(x^{c} \boldsymbol{\beta}_{c}+\right.$ $\epsilon_{1}$ ), with $x^{c}$ a vector of circumstances variables, $\boldsymbol{\beta}_{c}$ a vector of parameters to be estimated, and $\epsilon_{1}$ an unobserved residual. With $\hat{\boldsymbol{\beta}}_{c}$ estimated by ML, ${ }^{2}$ the simulated density in which any individual has the same fixed set of circumstances $\bar{x}^{c}$ (eg: at the mean values) can be simulated by:

$$
\tilde{h}_{e}\left(\cdot \mid \bar{x}^{c}\right)=\theta_{1}\left(\bar{x}^{c} \hat{\boldsymbol{\beta}}_{c}+\hat{\epsilon}_{1}\right) .
$$

After estimating this counterfactual effort distribution, we assign to each individual an effort level. In order to preserve the relative effort differences and remove the effect of circumstances, individual effort is predicted at the same quantile as in the observed distribution. ${ }^{3}$ From an econometric point of view, we predict individual effort with the following formula: for observation $i, \tilde{x}_{i}^{e}=\tilde{H}_{e}^{-1}\left(H_{e}\left(x_{i}^{e} \mid x^{c}\right) \mid \bar{x}^{c}\right)$, with $H_{e}(\cdot)$ the observed effort $\mathrm{CdF}$ and $\tilde{H}_{e}(\cdot)$ the simulated effort CdF. This rank preserving transformation firstly proposed by Juhn et al. [23] is widely used in the income distribution literature.

Secondly, we estimate an earnings distribution conditionally on circumstances and effort. The observed density can be written: $f_{y}\left(y \mid x^{e}, x^{c}\right)=\theta_{2}\left(x^{c} \gamma_{c}+x^{e} \gamma_{e}+\epsilon_{2}\right)$ and the simulated one:

$$
\tilde{f}_{y}\left(y \mid \tilde{x}^{e}, \bar{x}^{c}\right)=\theta_{2}\left(\bar{x}^{c} \hat{\gamma}_{c}+\tilde{x}^{e} \hat{\gamma}_{e}+\hat{\epsilon}_{2}\right) .
$$

To simulate this distribution one has to replace the observed effort level $x^{e}$ in the prediction with the one simulated $\tilde{x}^{e}$ in the step described above to remove the effect of circumstances playing through effort. Then, from Eq. 4 we assign individual earnings by preserving individual ranks and we predict earnings at the same quantile as in the observed earnings distribution. Hence, individual earnings free of any impact of circumstances are given by: $\tilde{y}_{i}=\tilde{F}_{y}^{-1}\left(F_{y}\left(\cdot \mid x^{c}, x^{e}\right) \mid \bar{x}^{c}, \tilde{x}^{e}\right)$. Lastly,

\footnotetext{
${ }^{2}$ The statistical framework is described in Section 2.3.

${ }^{3}$ For example, an individual at the 10th percentile of his observed conditional effort distribution will still be at the 10th percentile in the simulated effort distribution Eq. 3 .
} 
the unconditional distribution generating earnings inequality only due to effort is given by:

$$
\tilde{f}(y)=\int_{\tilde{x}^{e}} \tilde{f}_{y}\left(y \mid \tilde{x}^{e}, \bar{x}^{c}\right) \tilde{h}_{e}\left(\tilde{x}^{e} \mid \bar{x}^{c}\right) d \tilde{x}^{e} .
$$

This distribution provides an indirect measure of inequality of opportunity since it measures inequality of effort. A similar approach has been followed by Bourguignon et al. [8]. In their terminology, the direct effect of circumstances on earnings has been erased with the conditional earnings density $\tilde{f}\left(\cdot \mid \tilde{x}^{e}, \bar{x}^{c}\right)$, and the indirect effect of circumstances playing through effort has been removed with the conditional effort density $\tilde{h}\left(\cdot \mid \bar{x}^{c}\right)$. As Checchi and Peragine [12] point out, this approach comes back to removing between-circumstance groups inequality to keep only within group earnings differences. Hence with a decomposable inequality index, we can compute inequality of opportunity as the difference between inequality in distribution Eq. 2 and in distribution of Eq. 5. In the empirical section, using indexes from the entropy class we assess the degree of inequality of opportunity in the U.S. over the last 33 years due to these observable characteristics.

\subsection{The direct approach: measuring inequality of circumstances}

An alternative view considers that there is equality of opportunity if and only if individuals coming from different circumstances but exerting the same relative effort do benefit from the same earnings. To measure inequality of opportunity following this definition we can compare the observed distribution with a counterfactual one describing a hypothetical society in which individuals exert the same effort but come from different circumstances. The methodology is symmetrical to the first approach. In the first step, we simulate effort at the conditional mean but keep the observed circumstances differences to remove within group inequality. In the second step we simulate earnings conditional on the simulated effort and the observed set of circumstances.

Firstly, to simulate the counterfactual effort distribution, we keep circumstances differences but simulate individual effort at the conditional mean. The counterfactual effort density is given by:

$$
\tilde{\tilde{h}}_{e}\left(\cdot \mid x^{c}\right)=\theta_{1}\left(x^{c} \hat{\beta}_{c}+\hat{\epsilon}_{1}\right) .
$$

This distribution is identical to the observed one. Then, we predict individual effort at the mean of their conditional distribution: $\tilde{\tilde{x}}^{e}=\bar{x}^{e} \mid x^{c}=\tilde{\tilde{H}}_{e}^{-1}\left(H_{e}\left(\bar{x}^{e} \mid x^{c}\right) \mid x^{c}\right)$. With such a procedure we erase within group inequality due to relative effort differences and keep only between groups inequality due to circumstances.

Secondly, using the estimated conditional earnings density $f_{y}\left(y \mid x^{e}, x^{c}\right)=$ $\theta_{2}\left(x^{c} \gamma_{c}+x^{e} \gamma_{e}+\epsilon_{2}\right)$, we can simulate an earnings distribution in which every individual exerts the same effort but comes from different circumstances. To simulate this earnings distribution we replace the observed effort level with the simulated one from the first step and we keep the circumstances unchanged:

$$
\tilde{\tilde{f}}_{y}\left(y \mid x^{c}, \bar{x}^{e}\right)=\bar{\theta}_{2}\left(x^{c} \hat{\gamma}_{c}+\bar{x}^{e} \hat{\gamma}_{e}+\hat{\epsilon}_{2}\right) .
$$


From this simulated distribution, individual earnings are predicted at the mean of the conditional distribution to erase within group earnings differences due to effort: $\tilde{\tilde{y}}=\tilde{\tilde{F}}_{y}^{-1}\left(F_{y}\left(\bar{y} \mid x^{c}, x^{e}\right) \mid x^{c}, \bar{x}^{e}\right)$. The unconditional earnings distribution displaying only inequality due to circumstances is provided by:

$$
\tilde{\tilde{f}}(y)=\int_{x^{c}} \int_{\bar{x}^{e}} \tilde{\tilde{f}}_{y}\left(y \mid \bar{x}^{e}, x^{c}\right) \tilde{\tilde{h}}_{e}\left(\bar{x}^{e} \mid x^{c}\right) g\left(x^{c}\right) d \bar{x}^{e} d x^{c}
$$

Inequality in Eq. 7 provides a direct measure of inequality of opportunity prevailing in the observed distribution, since inequality of effort has been netted out. While the direct and indirect approaches are symmetric they can provide different assessments of inequality of opportunity; using both provides a test of their consistency. The next section describes how the micro-simulation framework is implemented.

\subsection{Statistical framework: semi-parametric-estimation of a distribution in the presence of covariates}

Measuring inequality of opportunity requires estimating Eqs. 5 and 7 and entails evaluating effort and earnings distributions conditionally on observed covariates. We implement a semi-parametric estimator for conditional distributions proposed by Donald et al. [16]. It builds on the duration models literature. Let $f(y \mid x)$ be the density. The classical following relation holds:

$$
f(y \mid x)=S(y \mid x) \times h(y \mid x) .
$$

With $h(y \mid x)$ the hazard rate and $S(y \mid x)$ the survivor function. The approach relies on a discrete time duration model. The distribution support is divided in $\mathrm{J}$ intervals: $\left[I_{0}, I_{1}\left[\ldots\left[I_{J-1}, I_{J}\left[\right.\right.\right.\right.$. Let $I_{j}$ represents interval $\left[I_{j-1}, I_{j}[\right.$. Using a proportional hazard rate model, it is possible to show (eg: Meyer [30]) that with a non-parametric baseline hazard rate, ${ }^{4}$ the hazard rate can be written:

$$
h\left(y \in I_{j} \mid x\right)=1-\exp \left[-\exp \left(x \boldsymbol{\beta}+\gamma_{j}\right)\right]
$$

With $\gamma_{j}=\log \left(\int_{I_{j-1}}^{I_{j}} h_{0}(u) d u\right)$ the integrated baseline hazard. In the previous case, any explanatory variable will have the same effect all along the distribution, which represents an obvious drawback. To overcome it, the support of the distribution is divided in $P$ segments, and $x \boldsymbol{\beta}$ is replaced by: $\Sigma_{p=1}^{P} 1\left(y \in I_{p}\right) x \boldsymbol{\beta}^{p}$, with $1(\cdot)$ a dummy variable. Hence, covariates are introduced as variables with time-varying coefficients in a duration model. Estimation of the parameters $\boldsymbol{\beta}$ and $\boldsymbol{\gamma}$ is nowadays usual by maximum likelihood. Derivation of the likelihood is provided in Meyer [30] an alternative approach is proposed in Jenkins [22]. After estimation of $\boldsymbol{\beta}$ and $\boldsymbol{\gamma}$ an estimation of the conditional density is provided by:

$$
\hat{f}\left(y \in I_{j} \mid x\right)=\hat{S}\left(y \in I_{j} \mid x\right)-\hat{S}\left(y \in I_{j-1} \mid x\right)
$$

The next section describes the PSID data.

\footnotetext{
${ }_{4}$ ie: piece-wise constant on all $\mathrm{J}$ intervals.
} 


\section{Data: the panel study of income dynamics}

\subsection{Data set}

Data come from the Michigan Panel Study of Income Dynamics. This data set is a household panel which began in 1968 and is still running. The panel was originally composed from around 5,000 households. Individuals have been followed annually from 1968 to 1997, then 1 year out of two, hence 1999 and 2001. We have used every wave from 1968 to $2001 .^{5}$ Children of households have been followed when they leave the family. This data base is a leading source for longitudinal studies on the U.S. It is possible to observe families over two generations. Individuals provide information on their monthly position on the labour market, their family situation, and their social environment. They declare their annual earnings and the number of hours worked during the previous year. In order to maximize sample sizes, we have used additional data to complete annual questionnaires. ${ }^{6}$ While the data is a panel, we will not use the panel structure of the data except for averaging earnings. The longitudinal nature of the study comes from the repetition of the procedure on the 32 cross sections. Finally, we have information about 22,759 households and 119,996 annual observations from 1968 to 2001.

\subsection{Main variables}

\subsubsection{Outcome variable: mean labour earnings}

Annual earnings include transitory variations and measurement errors. To neutralize these erratic components, earnings have been averaged up to 5 years. ${ }^{7}$ One may argue, however, that removing transitory earnings variations may lead to smooth the role of effort and then overestimate the relative importance of inequality of opportunities. To assess the sensitivity of this hypothesis we have implemented two alternative specifications without averaging annual earnings and with 3 years averages. Results will be presented with these three specifications. Finally, earnings data have been converted in 2000 dollars with the consumer price index.

\subsubsection{Circumstances}

Parental characteristics are associated with circumstance variables. They are on the one hand exogenous to individual choice and on the other hand partially correlated with their offspring's earnings. Individual circumstances include age, the number of years of education of both parents, the occupational group of the father (six groups) and the individual ethnic group (one dummy variable for individuals of the black

\footnotetext{
${ }^{5}$ Data of year $\mathrm{n}$ cover year $\mathrm{n}-1$. Hence the full period in 1967-2000.

${ }^{6}$ The following files have been used: Family history files, family income plus files, Hours of work and Wages Files, Retrospective occupation-industry. See http://simba.isr.umich.edu/Zips/zipSupp.aspx.

${ }^{7}$ The mean earnings refers to the middle year. If individuals are observed on a shorter period of time, their earnings is averaged on that subinterval. Examples: Mean earnings over 5 years in 1980 is the mean earnings from 1978 to 1982. For individuals observed only in 1980, 1979 and 1981, their mean earnings is computed over three rather than 5 years. If they are observed only in 1979 and 1981, then they do not belong to the 1980 sample.
} 
minority) and region of birth (one dummy variable if born in a southern state). This set of variables represents a description of social background which is still partial but it is available and comparable over 33 years. Using the longitudinal structure of the data it could have been possible to estimate the mean parental earnings in the first waves and their offsprings in the last waves. With this approach the results did not change much over the 1985-2001 period. However, samples would have been much smaller leading to potential selection biases. Therefore, in this study we restrict to parental information provided by the individual. However, it does not represent all the factors affecting earnings and exogenous to individual responsibility. Future works should try to take into account a thinner description of circumstances through family patrimony or inheritance for example.

\subsubsection{Effort}

Determining fair sources of inequality is a difficult and a controversial issue, since most earnings determinants are correlated with individual choice and at the same time with circumstances. Any strategy to disentangle the two may not be universally accepted. To that purpose, we follow the literature and effort is represented by individual characteristics including at least some individual choice component. Then to measure correctly effort we will keep only the share of the variance unaccounted for once conditioning on circumstances. Concerning earnings, human capital accumulation and labour supply behaviour are the major determinants of interindividual earnings differences. They will be the two effort characteristics.

More precisely, individual schooling attainment can be considered as an effort characteristics. It is at least partly the result of individual decisions. Admittedly, individual circumstances still play a role in the determination of education level. Hence, with binding credit constraints for education some individuals may not be able to invest as much as they would like. On American data, Carneiro and Heckman [11] and Cameron and Taber [10] reject this hypothesis. Admittedly, educational choices depend also on ability and expected future labour outcomes and these characteristics are partly inherited. It would be interesting to try to disentangle the effect of circumstances on education going through ability from the direct effect on schooling attainment. Unfortunately, the PSID does not provide ability scores to implement this decomposition.

The second effort variable is annual working hours. Earnings level is directly linked to the number of hours worked. From an ethical perspective, it seems fair that individuals working more receive a higher return. Nevertheless, working time choices result either from employment possibilities or public structure (transportation...) partly linked to inherited determinants. Moreover, the number of hours may not been chosen if individuals are constrained to work part time. As these effort variables are at the same time partially correlated to individual circumstances, in the empirical analysis we estimate education and working hours distributions conditionally on individual circumstances.

\subsection{Samples}

Samples are restricted to working male heads of household from 30 to 50 years old with positive annual earnings. Individuals are included whatever the number of periods they are observed, since earnings are averaged accordingly. The age 
range aims at providing a reasonable assessment of their permanent position on the labour market. For self-employed individuals we use their labour earnings as declared in the PSID. Admittedly, the longitudinal structure of the study comes from the repetition of the procedure on the 32 waves of the PSID, since the panel structure of the data has not been used except for averaging earnings. Finally, the analysis is restricted to men; for female labour supply a statistical modeling taking into account nonparticipation would need to be introduced and it is not the case in the present paper. In the panel, 65,427 individual-years respect these criteria. Table 9 in the Appendix presents sample sizes and inequality measures from 1968 to 2001 .

Table 1 shows that the composition of the American male working population has considerably changed over the period. With time, education levels have strongly increased. Hence for example, $48 \%$ had not finished high-school in 1968, but only $15 \%$ in 2001 . The share of the male working population with at least a high school degree reaches around $60 \%$ in $2001(36+23 \%)$, while it was only 33\% (20+13\%) in 1968. American males work on average 2300 hours annually all over the period.

Table 1 Descriptive statistics—-selected years

\begin{tabular}{|c|c|c|c|c|c|c|c|}
\hline & 1968 & 1975 & 1980 & 1985 & 1990 & 1995 & 2001 \\
\hline Earnings & $\begin{array}{l}42461 \\
(28447)\end{array}$ & $\begin{array}{l}47520 \\
(29678)\end{array}$ & $\begin{array}{l}46119 \\
(26193)\end{array}$ & $\begin{array}{l}45011 \\
(31745)\end{array}$ & $\begin{array}{l}43737 \\
(33721)\end{array}$ & $\begin{array}{l}47179 \\
(40854)\end{array}$ & $\begin{array}{l}49585 \\
(45176)\end{array}$ \\
\hline \multicolumn{8}{|l|}{ Effort } \\
\hline Hours & $\begin{array}{l}2333 \\
(623)\end{array}$ & $\begin{array}{l}2262 \\
(614)\end{array}$ & $\begin{array}{l}2246 \\
(615)\end{array}$ & $\begin{array}{l}2226 \\
(640)\end{array}$ & $\begin{array}{l}2251 \\
(598)\end{array}$ & $\begin{array}{l}2245 \\
(616)\end{array}$ & $\begin{array}{l}2289 \\
(582)\end{array}$ \\
\hline \multicolumn{8}{|l|}{ Education (\%) } \\
\hline$<$ Hg-school & .488 & .375 & .248 & .188 & .216 & .135 & .151 \\
\hline Hg-sc. degree & .174 & .167 & .185 & .195 & .212 & .250 & .250 \\
\hline College & .207 & .271 & .337 & .357 & .343 & .369 & .361 \\
\hline Adv. college & .129 & .185 & .228 & .259 & .227 & .244 & .237 \\
\hline \multicolumn{8}{|l|}{ Circumstances } \\
\hline Age & 39.92 & 39.61 & 37.70 & 37.17 & 38.14 & 39.38 & 40.26 \\
\hline Black $(\%)$ & .323 & .307 & .304 & .289 & .290 & .330 & .338 \\
\hline \multicolumn{8}{|c|}{ Education of the father (\%) } \\
\hline$<$ Hg-school & .840 & .764 & 649 & .578 & .566 & .484 & .376 \\
\hline Hg-sc. degree & .087 & .137 & .210 & .252 & .256 & .299 & .331 \\
\hline College & .035 & .044 & .070 & .083 & .074 & .093 & .120 \\
\hline Adv. College & .036 & .053 & .069 & .086 & .102 & .122 & .171 \\
\hline \multicolumn{8}{|c|}{ Education of the mother (\%) } \\
\hline$<$ Hg-school & .764 & .646 & .540 & .458 & .475 & .353 & .262 \\
\hline Hg-sc. degree & .177 & .264 & .326 & .383 & .367 & .441 & .467 \\
\hline College & .036 & .052 & .079 & .097 & .084 & .121 & .151 \\
\hline Adv. College & .021 & .036 & .052 & .060 & .072 & .084 & .117 \\
\hline \multicolumn{8}{|c|}{ Occupational group of the father (\%) } \\
\hline Professional & .044 & .063 & .079 & .101 & .110 & .114 & .143 \\
\hline Manager & .076 & .095 & .093 & .087 & .086 & .101 & .112 \\
\hline Clerical & .029 & .039 & .062 & .062 & .066 & .073 & .071 \\
\hline Craftsman & .163 & .191 & .199 & .215 & .201 & .268 & .265 \\
\hline Operative & .119 & .157 & .182 & .188 & .162 & .191 & .196 \\
\hline Farmer & .565 & .452 & .381 & .344 & .371 & .251 & .210 \\
\hline
\end{tabular}

Source: PSID, working men from 30 to 50. Hg-school: High school. College: between 13 and 16 years of education. Adv. College: $\geq 16$ years of education 
Individual circumstances appear in the bottom of the table. In 1968, 84\% of men had a father who had dropped of high-school, while they were less that half $(37 \%)$ in that situation in 2001. Mother's education has strongly increased and parallels father's education. Changes in parental education are impressive. In 1970, 6\% of mothers and $7 \%$ of fathers have been to college while nearly one out of three have been in 2001. The social position of the fathers has changed as well. These evolutions strengthen the need to control for the evolution of the circumstances' marginal distributions. A conditional approach would not have permitted distinguishing the changes in inequality of opportunity from the changes in the conditioning groups themselves.

\section{Changes in earnings inequality: 1968-2001}

In this section we summarize earnings inequality (ie inequality of outcome) from 1968 to 2001. In the next section we will compare it with the change in inequality of opportunity. In the U.S. the earnings distribution has considerably changed over the 1968-2001 period (Katz et al. [25], Levy and Murphy [28], Juhn et al. [23], Katz and Autor [24]). These studies use the CPS to assess the evolution of earnings inequality. This section develops a parallel study based on the PSID data.

Figure 1 represents these evolutions with the Theil index on PSID data with our three earnings specifications. Table 9 in Appendix provides other indexes. The figure

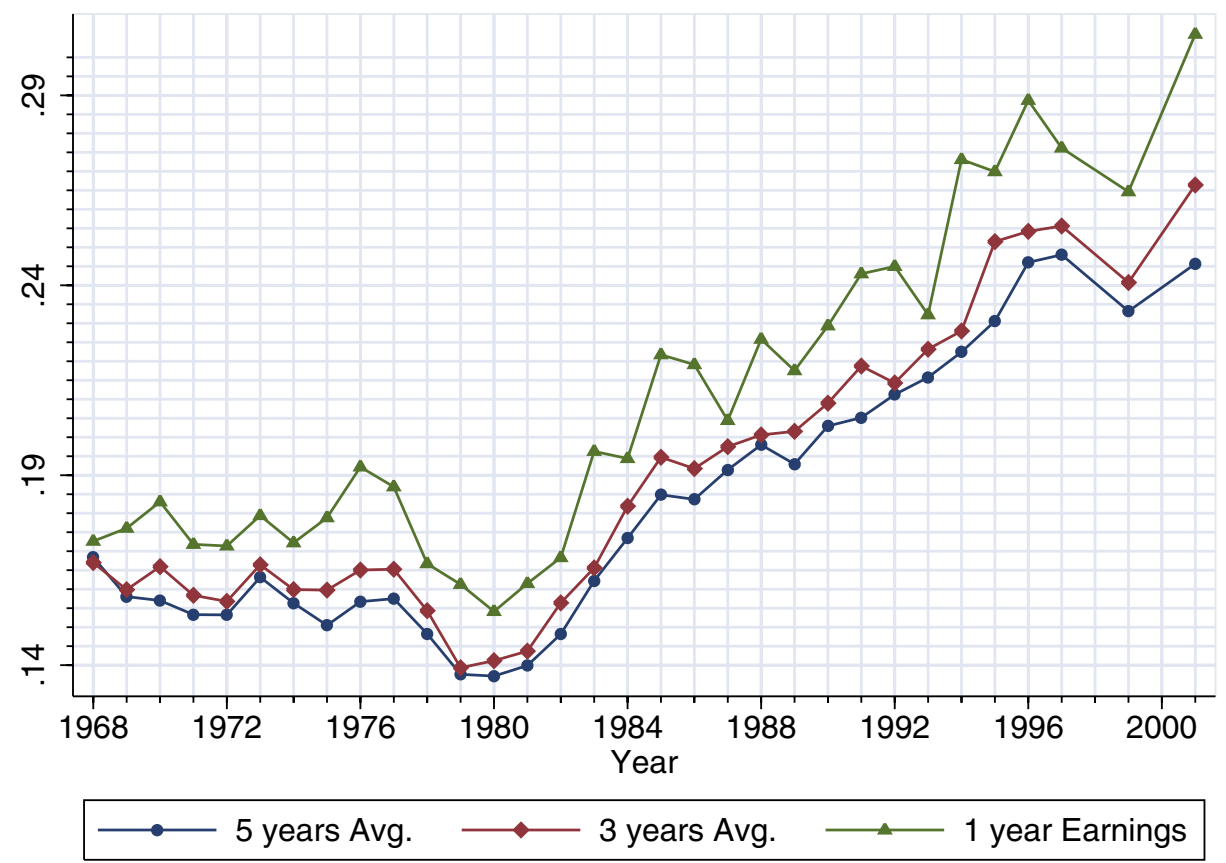

Fig. 1 Earnings inequality: Theil Index 1968-2001. Source: PSID, working men from 30 to 50 
Table 2 Lorenz dominance tests

\begin{tabular}{|c|c|c|c|c|c|c|}
\hline & 5 yea & earn & & & & \\
\hline & 1975 & 1980 & 1985 & 1990 & 1995 & 2000 \\
\hline 1970 & $=$ & $<$ & $>$ & $>$ & $>$ & $>$ \\
\hline 1975 & - & $?$ & $>$ & $>$ & $>$ & $>$ \\
\hline 1980 & - & - & $>$ & $>$ & $>$ & $>$ \\
\hline 1985 & - & - & - & $>$ & $>$ & $>$ \\
\hline 1990 & - & - & - & - & $?$ & $>$ \\
\hline 1995 & - & - & - & - & - & $=$ \\
\hline
\end{tabular}

Source: PSID, working men from 30 to 50. Lorenz dominance tests: >: The Lorenz curve in row dominates the Lorenz curve in column. ? The Lorenz curves are non-comparable. $=$ The Lorenz curves are equal

reflects the large increase in earnings inequality. The three earnings specifications display the same trend, while averaging decreases slightly the level by one or two Theil points. From then on, we comment only the 5 years earnings specification.

On this figure three periods appear. Firstly, from the end of the sixties to the midseventies the earnings dispersion has slightly changed. As already noted by Juhn et al. [23] this period displays only minor changes in the earnings distribution, the Theil index changing from .17 to .15 . Secondly, from the mid-seventies to the beginning of the eighties earnings inequality decreases slightly. Thirdly, from 1980 onwards large changes in the distribution have taken place, and earnings inequality has surged sharply until 2001. In the PSID data, the turning year is 1980, this is confirmed by Juhn et al. [23], Eckstein and Nagypal [18] and Gottschalk [21] with the CPS data. The Theil index growth rate from 1980 to 2001 is around $79 \%$ (from .13 in 1980 to .24 in 2001). However, during the second half of the nineties the growth of earnings inequality is weaker before increasing over the last few years of the sample as described by Lemieux [27], Autor et al. [5] and Gottschalk and Danziger [19].

Describing inequality through inequality indexes has two shortcomings. Firstly, some of the evolutions might not be statistically significant. Secondly, other inequality indexes having different properties might provide different conclusions. In order to answer the two weaknesses we implement Lorenz dominance tests. It is nonparametric and based on Davidson and Duclos [14]. The methodology is presented in more details in Lefranc et al. [26]. Lorenz dominance allows unanimity of a wide range of relative inequality indexes. ${ }^{8}$ The results of the tests are presented in Table 2 by 5 -year-intervals for the 5 years average specification. ${ }^{9}$ The tests reveal that the end of the seventies is the period with the lowest earnings inequality. After 1980, earnings inequality increases every year. Table 2 confirms the growth in earnings inequality in the eighties, while the relative stability of the second part of the nineties is reflected by the tests. On the whole, only two non-comparability show up out of 21

\footnotetext{
${ }^{8}$ See Atkinson [4].

${ }^{9}$ We do not test every year to keep results easy to read. Admittedly, the choice of selected years is quite arbitrary, but as our earnings specification is a 5 years average the results should be close for intermediate years.
} 
comparisons $(9.5 \%)$. Using an ordinal approach turns out not to be too restrictive, since most of the time the tests are able to rank the distributions. Finally, the tests reflect broadly our previous observations with the Theil indexes.

\section{Changes in equality of opportunity: 1968-2001}

To measure inequality of opportunity we compare the observed earnings distributions with two simulated distributions: one in which effort has been equalized and one in which circumstances are identical. In Section 5.1 we build these counterfactual distributions from 1968 to 2001. In Section 5.2 we measure changes in inequality of opportunity from these simulated distributions.

\subsection{Building counterfactual distributions}

To estimate counterfactual distributions, we estimate and simulate two conditional effort distributions (schooling, and hours worked) and one conditional earnings distribution. Then we build the counterfactual unconditional earnings distribution as described in Eqs. 5 and 7.

\subsubsection{Schooling distribution}

Heterogeneity in education levels represents a first source explaining interindividual earnings differences. Insofar as human capital investment decisions result at least partly from individual choices, years of schooling is an effort characteristic. We estimate and simulate conditional effort distributions using the methodology presented in Section 2.3 on each wave of the PSID from 1968 to 2001 . We use the number of years of education as dependent variable, it ranges from 1 to 17, then the baseline hazard rate is estimated with 17 dummy variables. Each explanatory variable has been crossed with two dummies to obtain different effects on different parts of the schooling distribution. The two explanatory segments run from 1 to 11 years and from 12 to 17 years to isolate individuals with a high-school diploma from high-school drop-outs. As the statistical framework comes from duration models, estimated coefficients can be interpreted as the effect on the conditional exit probability. Thus, for the schooling distribution a positive coefficient means an education level that is on average a quicker exit from the distribution, ie a lower schooling level. Symmetrically, a negative coefficient means a higher schooling level.

Table 3 presents results in 1968 and $2001 .^{10}$ Coming from the black minority is correlated with a lower schooling level since coefficients are positive. The effect is larger at the bottom of the distribution than at the top. This result reflects

\footnotetext{
${ }^{10}$ The estimated baseline hazard rate is of low interest here, it has not been reproduced but the dummies are significant at $1 \%$ taking increasing values.
} 
Table 3 Estimation of the conditional education distribution

\begin{tabular}{|c|c|c|c|c|}
\hline \multirow[t]{2}{*}{ Years of Ed. } & \multicolumn{2}{|l|}{1968} & \multicolumn{2}{|l|}{2001} \\
\hline & $1-11$ & $12-17$ & $1-11$ & $12-17$ \\
\hline$\overline{\text { Age }}$ & $\begin{array}{l}-.040^{* * * *} \\
(.007)\end{array}$ & $\begin{array}{l}.001 \\
(.009)\end{array}$ & $\begin{array}{l}-.028^{* * * *} \\
(.010)\end{array}$ & $\begin{array}{l}-.034 * * * \\
(.006)\end{array}$ \\
\hline Black & $\begin{array}{l}.692 * * * \\
(.086)\end{array}$ & $\begin{array}{l}.439 \text { *** } \\
(.167)\end{array}$ & $\begin{array}{l}.451 * * * \\
(.133)\end{array}$ & $\begin{array}{l}.045 \\
(.084)\end{array}$ \\
\hline Born south & $\begin{array}{l}.538 * * * \\
(.083)\end{array}$ & $\begin{array}{l}-.031 \\
(.129)\end{array}$ & $\begin{array}{l}-.220 * \\
(.124)\end{array}$ & $\begin{array}{l}.038 \\
(.071)\end{array}$ \\
\hline Educ. Father & $\begin{array}{l}-.110 \text { *** } \\
(.019)\end{array}$ & $\begin{array}{l}-.071 * * * \\
(.021)\end{array}$ & $\begin{array}{l}-.111 * * * * \\
(.024)\end{array}$ & $\begin{array}{l}-.072 * * * \\
(.015)\end{array}$ \\
\hline Educ. Mother & $\begin{array}{l}-.147 * * * \\
(.016)\end{array}$ & $\begin{array}{l}-.028 \\
(.020)\end{array}$ & $\begin{array}{l}-.135 * * * \\
(.024)\end{array}$ & $\begin{array}{l}-.093^{* * * *} \\
(.018)\end{array}$ \\
\hline Occupational g & e father (re & & & \\
\hline Professional & $\begin{array}{l}-.487 \\
(.301)\end{array}$ & $\begin{array}{l}-.958^{* * * *} \\
(.239)\end{array}$ & $\begin{array}{l}-.379 \\
(.268)\end{array}$ & $\begin{array}{l}-.943 * * * \\
(.138)\end{array}$ \\
\hline Manager & $\begin{array}{l}-1.464 * * * \\
(.272)\end{array}$ & $\begin{array}{l}-.942 * * * * \\
(.168)\end{array}$ & $\begin{array}{l}-.319 \\
(.238)\end{array}$ & $\begin{array}{l}-.743^{* * * *} \\
(.134)\end{array}$ \\
\hline Clerical & $\begin{array}{l}-.410 \\
(.320)\end{array}$ & $\begin{array}{l}-.495^{* * *} \\
(.251)\end{array}$ & $\begin{array}{l}-.734 * * \\
(.335)\end{array}$ & $\begin{array}{l}-.641 * * * \\
(.148)\end{array}$ \\
\hline Craftsman & $\begin{array}{l}-.440 * * * \\
(.123)\end{array}$ & $\begin{array}{l}.027 \\
(.152)\end{array}$ & $\begin{array}{l}-.458 * * * \\
(.164)\end{array}$ & $\begin{array}{l}-.207^{*} \\
(.108)\end{array}$ \\
\hline Operative & $\begin{array}{l}-.277 * * \\
(.126) \\
\end{array}$ & $\begin{array}{l}-.283 \\
(.178)\end{array}$ & $\begin{array}{l}-.333 * * \\
(.158) \\
\end{array}$ & $\begin{array}{l}.102 \\
(.113)\end{array}$ \\
\hline
\end{tabular}

Maximum Likelihood estimation. Source: PSID, men from 30 to 50.1551 observations in 1968, and 2246 observations in 2001. Educ. father (resp. mother): number of schooling years of the father (resp. mother). Born south: Born in a southern state. Standard errors in brackets.

$* p<0.10 ; * * p<0.05 ; * * *<0.01$

the large racial educational inequalities in the United States as described by Neal [31]. While the age coefficient is negative meaning that older men have a higher probability of having more schooling, they are not always significant and are ten times less important than ethnicity (ratio of the parameters). Parental characteristics have the expected sign: individuals coming from privileged backgrounds have more education. Father's education is significant all along the distribution and its effect is remarkably close in 1968 and in 2001. While mother's education appears important at low education levels only. Lastly, the occupational group of the father is strongly significant, as sons of farmers perform lower than the other origin social groups and sons of managers and professionals reach higher schooling levels.

We predict two education distributions. In the first one (indirect approach) we erase circumstances differences to keep only inequality due to effort. As previously mentioned, we consider age, the color of the skin, education of both parents, the region of birth and the occupation of the father as factors outside individuals' responsibility. Education of both parents is set at 13 years, his occupation at professional, the region of birth as not being the south and the ethnic group as not belonging to the black minority. In the second simulated distribution (direct approach) we predict the 
same (mean) education to individuals coming from the same circumstances to erase effort differences but we let the circumstances at their observed levels.

Table 4 presents the observed and the two simulated schooling distributions. As expected the simulations reduce the dispersion of educational attainment since the standard error of the schooling distribution decreases from 3.52 in 1968 (2.49 in 2001) to 2.05 (resp. 1.17 in 2001) when we erase circumstances differences and to 2.24 (resp. 1.31) years of education when removing effort differences. Equalizing circumstances seems more important at the bottom of the distribution, since the lower $20 \%$ goes from 8 to 11 years in 1968 and from 12 to 14 years in 2001, while equalizing effort do not change the lower part of the distribution at 8 years in 1968 and 12 years in 2001. Interestingly and symmetrically, differences of effort impact more the top of the schooling distribution than differences of circumstances, since the top of the distribution decreases more when equalizing effort (see Table 4), while the top of the distribution remains unaltered when erasing circumstances differences.

\subsubsection{Labour supply distribution}

Labour supply is our second effort characteristic. The impact of the number of hours worked must not be corrected on earnings differentials. Working hours distributions are estimated conditionally on social background (education of the parents, and occupation of the father), ethnic origin, age and region of birth as well as education. The dependent variable is the annual number of hours worked. To allow explanatory variables to have different effects, we divide the support of the distribution into two segments: from 400 to 2000 hours, which corresponds to less than a fulltime job, and over 2000 hours. Around $85 \%$ men are fulltime workers. With this approach, we isolate part-time from full-time workers. To estimate the baseline hazard rate, the support is divided into 50 intervals from 400 hours to 4000 hours.

Results are presented in Table 5 for 1968 and 2001. More educated men have a larger probability of working longer in the 2 years, since estimated coefficients are negative and significant. Individuals coming from an ethnic minority have a larger probability of working less (positive coefficients). There do not seem to exist marked differences linked to age. Concerning parental characteristics it is possible to see a rather weak partial correlation with parental education, while occupation of the

Table 4 Observed and simulated schooling distributions

\begin{tabular}{|c|c|c|c|c|c|c|}
\hline & 1968 & & & 2001 & & \\
\hline & Observed & Simulated & & Observed & Simulated & \\
\hline & & Indirect eop & $\overline{\text { Direct eop }}$ & & Indirect eop & $\overline{\text { Direct eop }}$ \\
\hline .20 & 8 & 11 & 8 & 12 & 14 & 12 \\
\hline .40 & 10 & 12 & 10 & 12 & 14 & 12 \\
\hline .60 & 12 & 12 & 11 & 14 & 15 & 12 \\
\hline .80 & 13 & 16 & 12 & 16 & 16 & 14 \\
\hline Std & 3.52 & 2.05 & 2.24 & 2.49 & 1.17 & 1.31 \\
\hline $\mathrm{N}$ & 1561 & 1561 & 1561 & 2246 & 2246 & 2246 \\
\hline
\end{tabular}

CdFs. Observed: observed distribution of years of education. Indirect Eop: simulated distribution equalizing circumstances. Direct Eop: Simulated distribution with equalizing effort. Std: Standard deviation 
Table 5 Working hours distribution estimation

\begin{tabular}{|c|c|c|c|c|}
\hline \multirow[t]{2}{*}{ Hours } & \multicolumn{2}{|l|}{1968} & \multicolumn{2}{|l|}{2001} \\
\hline & $400-2000$ & $2000-4000$ & $400-2000$ & $2000-4000$ \\
\hline \multirow[t]{2}{*}{ Age } & -.001 & .006 & .009 & $.009 *$ \\
\hline & $(.006)$ & $(.007)$ & $(.006)$ & $(.005)$ \\
\hline \multirow[t]{2}{*}{ Education } & $-.031 * *$ & $-.028 *$ & $-.049 * * *$ & -.013 \\
\hline & $(.013)$ & $(.016)$ & $(.014)$ & $(.014)$ \\
\hline \multirow[t]{2}{*}{ Black } & $.324 * * *$ & $.222 * *$ & $.419^{* * * *}$ & .080 \\
\hline & $(.086)$ & (.108) & $(.078)$ & $(.079)$ \\
\hline \multirow[t]{2}{*}{ Born South } & $-.211 * * *$ & -.015 & -.103 & -.035 \\
\hline & $(.080)$ & $(.091)$ & $(.071)$ & $(.067)$ \\
\hline \multirow[t]{2}{*}{ Educ. father } & -.012 & .018 & -.015 & $.041 * * *$ \\
\hline & $(.016)$ & $(.017)$ & $(.015)$ & $(.015)$ \\
\hline \multirow[t]{2}{*}{ Educ. mother } & $-.024^{*}$ & .004 & -.024 & -.019 \\
\hline & $(.014)$ & $(.016)$ & $(.016)$ & $(.017)$ \\
\hline \multicolumn{5}{|c|}{ Occupation of the father (ref: Farmer) } \\
\hline \multirow[t]{2}{*}{ Professional } & -.656 & -.450 & $-1.438 * * *$ & $-2.968 * * *$ \\
\hline & $(.411)$ & $(.638)$ & $(.402)$ & $(.819)$ \\
\hline \multirow[t]{2}{*}{ Manager } & $-1.129 * * *$ & -.623 & $-1.669 * * *$ & $-3.102 * * *$ \\
\hline & $(.379)$ & $(.604)$ & $(.390)$ & $(.812)$ \\
\hline \multirow[t]{2}{*}{ Clerical } & $-.791 *$ & -.673 & $-1.461 * * *$ & $-3.120 * * *$ \\
\hline & $(.410)$ & $(.642)$ & $(.401)$ & $(.818)$ \\
\hline \multirow[t]{2}{*}{ Craftsman } & $-1.011 * * *$ & -.333 & $-1.328 * * *$ & $-3.022 * * *$ \\
\hline & $(.349)$ & $(.582)$ & $(.366)$ & $(.803)$ \\
\hline \multirow[t]{2}{*}{ Operative } & $-.883^{* *}$ & -.235 & $-1.431 * * *$ & $-2.938 * * *$ \\
\hline & $(.344)$ & $(.587)$ & $(.362)$ & $(.801)$ \\
\hline
\end{tabular}

Maximum Likelihood estimation of the conditional working time distribution. Source PSID: working men from 30 to 50. Education: years of education. Educ Father (Educ Mother): number of years of schooling of the father (mother). South: Born in a southern state. In brackets standard errors.

$* p<0.10 ; * * p<0.05 ; * * p<0.01$

father is more correlated with labour supply decisions especially at the bottom of the distribution. Sons of farmers work less than the other social groups. Compared to their impact on educational choices, circumstances variables have a weaker impact on labour supply decisions.

Table 6 Observed and simulated labour supply distributions

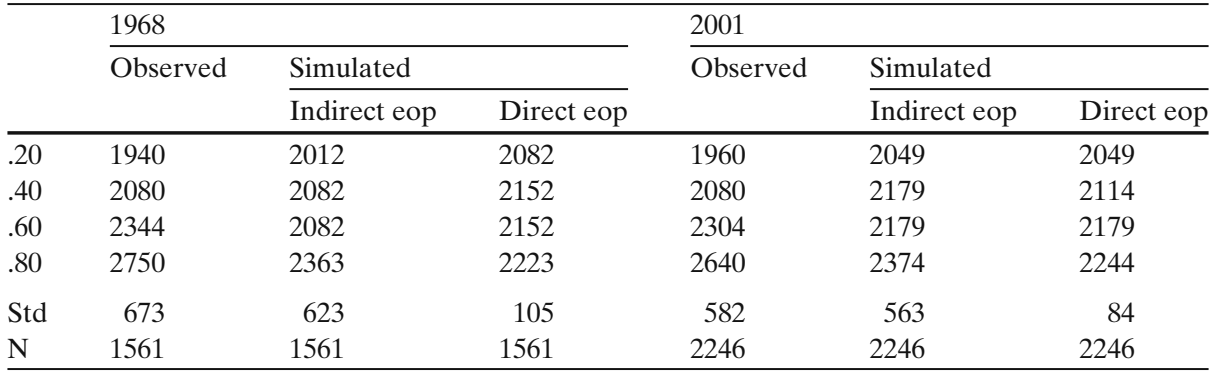

CdFs. Observed: observed distribution of hours worked. Indirect Eop: simulated distribution with equalized circumstances. Direct Eop: Simulated distribution with equalized effort. Std: Standard deviation 
For each individual we simulate two labour supply choices. In the indirect approach we equalize circumstances, while in the direct approach we equalize effort. Table 6 provides the results of these simulations. Equalizing effort has a much larger impact on hours worked than equalizing circumstances since the standard deviation is divided by six when we remove effort differences, while it is nearly unchanged when we remove circumstances differences. Contrary to schooling decision, effort play a larger role than circumstances in explaining labour supply choices. This larger effect comes from the larger reduction of labour supply differences at the top than at the bottom in the direct approach.

\subsubsection{Earnings distribution}

Table 7 displays estimated coefficients for the conditional earnings distributions in 1968 and 2001. The support has been divided into 50 segments until the 99th

Table 7 Conditional earnings distribution estimation

\begin{tabular}{|c|c|c|c|c|}
\hline \multirow[t]{2}{*}{ \% support } & \multicolumn{2}{|l|}{1968} & \multicolumn{2}{|l|}{2001} \\
\hline & $0-50$ & $50-100$ & $0-50$ & $50-100$ \\
\hline$\overline{\text { Age }}$ & $\begin{array}{l}-.233 * * * \\
(.086)\end{array}$ & $\begin{array}{l}-.318^{* * * *} \\
(.115)\end{array}$ & $\begin{array}{l}-.129 * \\
(.075)\end{array}$ & $\begin{array}{l}-.202 * * \\
(.090)\end{array}$ \\
\hline$A g e^{2}$ & $\begin{array}{l}.003 * * \\
(.001)\end{array}$ & $\begin{array}{l}.004 * * * \\
(.001)\end{array}$ & $\begin{array}{l}.001 \\
(.001)\end{array}$ & $\begin{array}{l}.002 * \\
(.001)\end{array}$ \\
\hline Education & $\begin{array}{l}-.160 * * * \\
(.013)\end{array}$ & $\begin{array}{l}-.161 * * * \\
(.019)\end{array}$ & $\begin{array}{l}-.151^{* * * *} \\
(.013)\end{array}$ & $\begin{array}{l}-.099 * * * \\
(.016)\end{array}$ \\
\hline Hours & $\begin{array}{l}-.197 * * * \\
(.024)\end{array}$ & $\begin{array}{l}-.190 * * * \\
(.050)\end{array}$ & $\begin{array}{l}-.197 * * * \\
(.020)\end{array}$ & $\begin{array}{l}-.085^{* * * *} \\
(.030)\end{array}$ \\
\hline Hours $^{2}$ & $\begin{array}{l}.003 * * * \\
(.000)\end{array}$ & $\begin{array}{l}.003 * * * * \\
(.001)\end{array}$ & $\begin{array}{l}.003 * * * \\
(.000)\end{array}$ & $\begin{array}{l}.001^{*} \\
(.001)\end{array}$ \\
\hline Black & $\begin{array}{l}.535 * * * \\
(.080)\end{array}$ & $\begin{array}{l}.433^{* * * *} \\
(.157)\end{array}$ & $\begin{array}{l}.168 * * \\
(.071)\end{array}$ & $\begin{array}{l}.080 \\
(.092)\end{array}$ \\
\hline Born South & $\begin{array}{l}.651 * * * \\
(.074)\end{array}$ & $\begin{array}{l}.196^{*} \\
(.116)\end{array}$ & $\begin{array}{l}.284 * * * \\
(.065)\end{array}$ & $\begin{array}{l}.138^{*} \\
(.077)\end{array}$ \\
\hline Educ. Father & $\begin{array}{l}-.052 * * * \\
(.016)\end{array}$ & $\begin{array}{l}-.002 \\
(.019)\end{array}$ & $\begin{array}{l}-.027 * * \\
(.014)\end{array}$ & $\begin{array}{l}-.022 \\
(.016)\end{array}$ \\
\hline Educ. Mother & $\begin{array}{l}-.014 \\
(.015)\end{array}$ & $\begin{array}{l}.001 \\
(.018)\end{array}$ & $\begin{array}{l}-.041^{* * * *} \\
(.015)\end{array}$ & $\begin{array}{l}-.045^{* *} \\
(.019)\end{array}$ \\
\hline Occupation of & (ref: Farme & & & \\
\hline Manager & $\begin{array}{l}.085 \\
(.210)\end{array}$ & $\begin{array}{l}-.559^{* * *} \\
(.219)\end{array}$ & $\begin{array}{l}-.507^{* * * *} \\
(.133)\end{array}$ & $\begin{array}{l}-.339 * * \\
(.153)\end{array}$ \\
\hline Professional & $\begin{array}{l}-.738 * * * \\
(.203)\end{array}$ & $\begin{array}{l}-.465^{\text {**** }} \\
(.153)\end{array}$ & $\begin{array}{l}-.808^{* * * *} \\
(.140)\end{array}$ & $\begin{array}{l}-.401 * * * * \\
(.145)\end{array}$ \\
\hline Clerical & $\begin{array}{l}-.431 * \\
(.250)\end{array}$ & $\begin{array}{l}-.608^{* * *} \\
(.233)\end{array}$ & $\begin{array}{l}-.322 * * \\
(.145)\end{array}$ & $\begin{array}{l}-.145 \\
(.167)\end{array}$ \\
\hline Craftsman & $\begin{array}{l}-.507^{* * * *} \\
(.114)\end{array}$ & $\begin{array}{l}-.154 \\
(.122)\end{array}$ & $\begin{array}{l}-.399 * * * \\
(.090)\end{array}$ & $\begin{array}{l}.008 \\
(.127)\end{array}$ \\
\hline Operative & $\begin{array}{l}-.358^{* * * *} \\
(.117) \\
\end{array}$ & $\begin{array}{l}.064 \\
(.147) \\
\end{array}$ & $\begin{array}{l}-.235^{* * *} \\
(.089) \\
\end{array}$ & $\begin{array}{l}.312 * * \\
(.138) \\
\end{array}$ \\
\hline
\end{tabular}

Maximum Likelihood earnings distribution estimation. In brackets standard errors.

$* p<0.10 ; * * p<0.05 ; * * * p<0.01$ 
percentile. It is segmented a second time into two intervals for the estimation of the parameters. Table 7 shows that more educated and older men have higher earnings (coefficients are significant and negative). As expected individuals working more have higher annual earnings, while those coming from the black minority have lower earnings but the effect is larger in 1968 than in 2001. Inequality of opportunity transmitted by ethnic origin seems weaker in 2001 than in 1968; these results reflect somewhat Neal [31] who finds that earnings inequalities have decreased while schooling inequalities are constant over the period. Having an educated father is correlated with higher earnings, but the effect is much more important at the bottom of the distribution than at the top. Finally, sons of farmers receive lower earnings. After estimating the earnings distribution, we simulate on the one hand individual earnings at fixed circumstances and on the other individual earnings at fixed effort. From these simulated conditional distributions we build the unconditional earnings counterfactual distributions. The next section uses these counterfactual distributions to document the change in inequality of opportunity.

\subsection{Changes in inequality of opportunity}

To assess the decrease in inequality resulting from our two approaches we use scalar inequality indexes. While the analysis looses generality when using specific inequality indexes, it is still very common in the income distribution literature. ${ }^{11} \mathrm{We}$ pay special attention to indexes of the entropy class, since they are decomposable.

Figure 2 displays Theil indexes on each wave of the PSID from 1968 to 2001 for the 5 years average specification. Three curves appear in this figure. The first represents total inequality computed on the observed earnings distribution. It indicates the changes in outcome inequality. The two other represent inequality of opportunity with the direct and the indirect approaches. Inequality of opportunity with the direct approach is measure directly from the counterfactual distributions, while inequality of opportunity with the indirect approach is measured differencing total inequality and effort inequality provided by the counterfactual distributions. According to the philosophers on responsibility at least this part of inequality must be corrected.

\subsubsection{On average between 20 and $43 \%$ of inequality is inherited}

Strikingly, the two approaches provide very similar patterns of inequality of opportunity levels from 1968 to 2001. The Theil indexes with the indirect approach in Fig. 2 are slightly higher and a little bit more changing in the mid-eighties, but on average these two measures provide the same inequality of opportunity level all along the period. Inequality transmitted by these observable social background characteristics ranges from 0.035 to 0.061 with the direct approach, and from 0.02 to 0.094 with the indirect approach, with an average value over the period at 0.048 and 0.056 . It represents the hardcore inequality. Comparing the level of inequality of opportunity

\footnotetext{
${ }^{11}$ Dinardo et al. [15] use indexes to assess the changes in their distribution after a semi-parametric estimation. Similar procedures are implemented by Bourguignon et al. [7, 8] and Mata and Machado [29].
} 


\section{Theil}

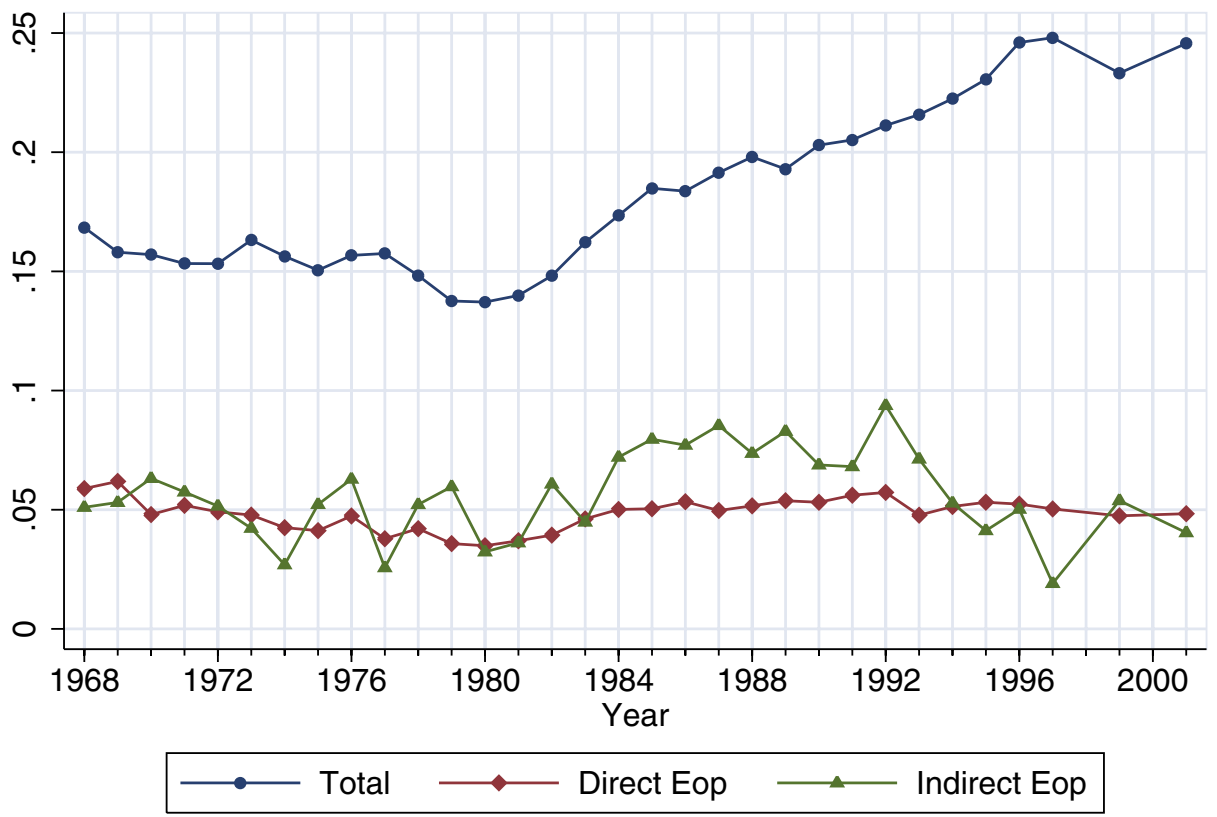

Fig. 2 Inequality of opportunity and inequality of outcome. Source: PSID, working men from 30 to 50. Total: earnings inequality. Direct Eop: Inequality of opportunity erasing effort differences. Indirect Eop: Inequality of Opportunity erasing circumstances differences

with the level of inequality of outcome, we can compute the share of inequality that is inherited.

Table 8 displays the minimum, maximum and mean annual share of inequality of opportunity in inequality of outcome from 1968 to 2001. Using other decomposable inequality indexes of the entropy class (the mean logarithmic deviation, and the half squared coefficient of variation) we find a mean share varying between $20 \%$ to $28 \%$ with the direct approach and between $31 \%$ and $41 \%$ in the indirect approach. Using alternative inequality indexes, the Gini index and the standard deviation of logs, we still find the same range of estimates varying from $26 \%$ to $43 \%$. These results seem to be weakly sensitive to the index chosen. Finally, we observe that averaging earnings increases slightly the share of inequality of opportunity in inequality of outcome. These results should be considered keeping in mind that we do not observe every earnings determinants. It is possible that unobserved circumstances characteristics would change the results. The problem is that the potential sign of the bias is unclear (See Bourguignon et al. [8] for a discussion on that point). However our appraisal of inequality of opportunity does include the effect of observed circumstances and unobserved circumstances correlated with them.

\subsubsection{Evolution: a sharp drop of inequality of opportunity}

While the mean share of inequality of opportunity seems robust, however looking only at the mean does not inform on its change over time. Figure 2 shows that while 
Table 8 Share of inequality of opportunity in inequality of outcome

\begin{tabular}{|c|c|c|c|c|c|c|c|c|c|c|}
\hline & \multicolumn{5}{|c|}{ Direct approach } & \multicolumn{5}{|c|}{ Indirect approach } \\
\hline & Theil & Mld & $\mathrm{GE}(2)$ & Sdl & Gini & Theil & Mld & $\mathrm{GE}(2)$ & Sdl & Gini \\
\hline \multicolumn{11}{|c|}{ Annual earnings } \\
\hline Mean & .236 & .233 & .172 & .353 & .322 & .276 & .294 & .343 & .279 & .247 \\
\hline Minimum & .150 & .164 & .075 & .239 & .244 & .073 & .100 & .169 & .183 & .146 \\
\hline Maximum & .337 & .342 & .256 & .472 & .419 & .418 & .482 & .445 & .356 & .338 \\
\hline \multicolumn{11}{|c|}{ Three years average earnings } \\
\hline Mean & .260 & .271 & .192 & .413 & .346 & .305 & .328 & .400 & .317 & .258 \\
\hline Minimum & .172 & .190 & .099 & .319 & .267 & .079 & .113 & .206 & .205 & .150 \\
\hline Maximum & .371 & .388 & .287 & .524 & .444 & .438 & .565 & .530 & .408 & .350 \\
\hline \multicolumn{11}{|c|}{ Five years average earnings } \\
\hline Mean & .270 & .284 & .201 & .430 & .355 & .316 & .343 & .418 & .327 & .263 \\
\hline Minimum & .186 & .208 & .115 & .349 & .281 & .081 & .120 & .219 & .220 & .153 \\
\hline Maximum & .375 & .394 & .292 & .530 & .447 & .446 & .554 & .538 & .411 & .359 \\
\hline
\end{tabular}

Mean, minimum and maximum annual share of inequality of opportunity in inequality of outcome from 1968 to 2001. Mld: Mean logarithmic deviation, GE(2): Half squared coefficient of variation. Sdl: Standard deviation of logs

total inequality has increased steadily inequality of opportunity has remained around .05 Theil points all along the period. With the direct approach, the share of inequality of opportunity has nearly been divided by two dropping from 33\% in 1968 to 18.6 in 2001. The correlation between the share of inequality of opportunity and the level of inequality of outcome turns out to be negative at -.06 . Henceforth, the increase in total earnings inequality is mainly due to the increase in inequality generated by other earnings determinants called effort. This different evolution strengthens that inequality of opportunity and inequality of outcome are clearly two different concepts providing different pictures of the American society.

These results can be compared with Bourguignon et al. [8] on Brazilian data during the nineties. These authors assess inequality of opportunity at around $25 \%$ of total earnings inequality. While one might have expected large differences between Brazil and the U.S. these results are very similar to ours. International comparisons between countries of such different development levels are difficult, and the parallel must be read with great caution. Strikingly, these results do not comfort the intuition that inequality of opportunity would be much lower in the U.S than in Brazil. Assessing the reasons of such a small difference is not the topic of this paper. It pleads, though, for international comparisons of inequality of opportunity as in Lefranc et al. [26].

\section{Conclusion}

In 2001 the U.S. land of opportunities keeps displaying large earnings inequalities correlated with individual social background. This paper concludes that in the period between 1968 and 2001 between $20 \%$ and $43 \%$ of earnings inequality is inherited. 
This share has decreased over the last few years. A more complete modeling of disposable income acquisition would be necessary to measure the extent of inequality of opportunity in living standards. Though our study represents only a first step in that direction, it presents a decomposition of the different channels producing earnings inequalities throughout the life cycle. Although simple, the decomposition suggests that inherited inequalities have above all a major impact on human capital accumulation decisions. They have a weaker impact on labour supply choices.

The relative drop of inequality of opportunity in inequality in outcome is the major conclusion of our analysis. Three interpretations of the result are possible. Firstly, the American population may exert nowadays more heterogeneous effort levels than in the past. Alternatively, for a given circumstances group it is possible to observe more earnings variation, since effort differences are defined by within group inequality. Since Juhn et al. [23] these kinds of phenomena have been much discussed in the literature, it is nowadays commonly admitted that within-group inequality represents a large share of earnings inequality growth, see Lemieux [27] or Autor et al. [5] for recent assessments.

Secondly, the return to effort may have increased. This explanation is directly linked with analyses [9] demonstrating that return to education is higher today than 20 years ago, and that its growth rate has been larger for more educated workers. ${ }^{12}$ Both interpretations are possible. There is no reason to think that one is better than the other, both return to effort and within-group heterogeneity could have increased simultaneously. It would be interesting in future work to try to disentangle the two phenomena. ${ }^{13}$

Thirdly, some unobservable circumstance characteristics may be more relevant nowadays than before. It may be possible that the increase in inequality of effort is in reality due to these factors that have been ranked as effort due to the difficulty to observe them. In that case, the issue is to find out what these factors might be and how to measure them. In any case they must be uncorrelated with the included circumstances characteristics. Admittedly, our measure of circumstances is imperfect but due to data limitation it is difficult to go further. From a theoretical point of view see O'Neil et al. [32] for an analysis of the potential consequences of imperfect measurement in intergenerational transition matrix. Without any more details on the potential unobserved circumstances it is difficult to conclude on that point.

Finally, the analysis implemented in this paper demonstrates that the evolution of earnings inequality in the U.S. over 30 years changes according to different conceptions of social justice. From a public policy perspective, it stresses the importance of the definition of inequality. Whether policymakers aim at preserving equality of opportunity or correcting total inequality, the definition of inequality matters.

\footnotetext{
${ }^{12}$ More precisely, for young and old college graduates, and for young high school graduates.

${ }^{13}$ It represents a limit of our nonlinear modeling. Since it precludes considering estimated coefficients as return of explanatory variables and then using a Blinder-Oaxaca decomposition.
} 
Acknowledgements I am grateful to Alain Trannoy for helpful comments. Other comments and suggestions were offered by Tony Atkinson, Thomas Brodaty, Brigitte Dormont, Eric Maurin, Arnaud Lefranc, Dirk Van de Gaer and participants in seminars at ADRES Université Paris Dauphine, THEMA (Université de Cergy-Pontoise), GAINS (Université du Maine) and CES (Université Paris 1). I thank the anonymous referees who helped me improving the quality of the paper. However, any mistake in fact or in interpretation remains mine.

\section{Appendix}

\section{A.1 Earnings inequality measures}

Table 9 Earnings inequality measures 1968-2001

\begin{tabular}{|c|c|c|c|c|c|c|c|}
\hline \multirow[t]{2}{*}{ Year } & \multirow[t]{2}{*}{ Obs. } & \multicolumn{6}{|c|}{ Earnings inequality } \\
\hline & & Gini & Mld & $\mathrm{P} 50 / \mathrm{P} 10$ & P90/P50 & Sdl & Theil \\
\hline 1968 & 1,561 & 0.31 & 0.17 & 2.15 & 1.87 & 0.59 & 0.17 \\
\hline 1969 & 1,415 & 0.30 & 0.16 & 2.16 & 1.87 & 0.58 & 0.16 \\
\hline 1970 & 1,396 & 0.30 & 0.16 & 2.14 & 1.83 & 0.57 & 0.16 \\
\hline 1971 & 1,387 & 0.29 & 0.15 & 2.07 & 1.83 & 0.56 & 0.15 \\
\hline 1972 & 1,404 & 0.29 & 0.15 & 2.11 & 1.83 & 0.56 & 0.15 \\
\hline 1973 & 1,397 & 0.30 & 0.16 & 2.17 & 1.81 & 0.57 & 0.16 \\
\hline 1974 & 1,405 & 0.30 & 0.15 & 2.15 & 1.82 & 0.55 & 0.16 \\
\hline 1975 & 1,382 & 0.29 & 0.15 & 2.06 & 1.80 & 0.55 & 0.15 \\
\hline 1976 & 1,390 & 0.30 & 0.15 & 2.16 & 1.80 & 0.56 & 0.16 \\
\hline 1977 & 1,478 & 0.30 & 0.15 & 2.06 & 1.86 & 0.55 & 0.16 \\
\hline 1978 & 1,551 & 0.29 & 0.15 & 2.07 & 1.78 & 0.54 & 0.15 \\
\hline 1979 & 1,655 & 0.28 & 0.14 & 2.11 & 1.75 & 0.57 & 0.14 \\
\hline 1980 & 1,676 & 0.28 & 0.14 & 2.14 & 1.73 & 0.54 & 0.14 \\
\hline 1981 & 1,690 & 0.28 & 0.14 & 2.13 & 1.74 & 0.56 & 0.14 \\
\hline 1982 & 1,745 & 0.29 & 0.16 & 2.23 & 1.76 & 0.59 & 0.15 \\
\hline 1983 & 1,780 & 0.30 & 0.17 & 2.33 & 1.83 & 0.60 & 0.16 \\
\hline 1984 & 1,923 & 0.31 & 0.18 & 2.28 & 1.83 & 0.62 & 0.17 \\
\hline 1985 & 2,058 & 0.32 & 0.19 & 2.35 & 1.89 & 0.63 & 0.18 \\
\hline 1986 & 2,147 & 0.32 & 0.19 & 2.34 & 1.91 & 0.63 & 0.18 \\
\hline 1987 & 2,244 & 0.33 & 0.19 & 2.32 & 1.90 & 0.64 & 0.19 \\
\hline 1988 & 2,327 & 0.33 & 0.19 & 2.28 & 1.91 & 0.64 & 0.20 \\
\hline 1989 & 2,420 & 0.33 & 0.19 & 2.32 & 1.92 & 0.63 & 0.19 \\
\hline 1990 & 3,074 & 0.33 & 0.20 & 2.28 & 1.97 & 0.64 & 0.20 \\
\hline 1991 & 3,123 & 0.33 & 0.20 & 2.30 & 1.97 & 0.64 & 0.21 \\
\hline 1992 & 3,276 & 0.34 & 0.20 & 2.33 & 1.97 & 0.64 & 0.21 \\
\hline 1993 & 3,257 & 0.34 & 0.21 & 2.32 & 1.99 & 0.65 & 0.22 \\
\hline 1994 & 2,899 & 0.34 & 0.21 & 2.17 & 2.02 & 0.67 & 0.22 \\
\hline 1995 & 2,897 & 0.35 & 0.22 & 2.22 & 2.05 & 0.66 & 0.23 \\
\hline 1996 & 2,893 & 0.35 & 0.23 & 2.23 & 2.08 & 0.69 & 0.25 \\
\hline 1997 & 2,177 & 0.35 & 0.22 & 2.06 & 2.12 & 0.66 & 0.25 \\
\hline 1999 & 2,154 & 0.35 & 0.22 & 2.08 & 2.17 & 0.66 & 0.23 \\
\hline 2001 & 2,246 & 0.35 & 0.22 & 2.05 & 2.18 & 0.68 & 0.25 \\
\hline & 65,427 & & & & & & \\
\hline
\end{tabular}

Source: PSID, working 30 to 50 men. Five years average earnings. Mld: Mean logarithmic deviation, Sdl: Standard deviation of logs 


\section{References}

1. Alesina, A., Glaeser, E.: Fighting Poverty in the US and Europe: A World of Difference. Oxford University Press, London (2006)

2. Alesina, A., La Ferrara, E.: Preferences of redistribution in the land of opportunities. J. Public Econ. 89(5-6), 897-931 (2005)

3. Arneson, R.: Equality and equal opportunity for welfare. Philos. Stud. 56, 77-93 (1989)

4. Atkinson, A.B.: On the measurement of inequality. J. Econ. Theory 18, 59-80 (1970)

5. Autor, D.H., Katz, L.F., Kearney, M.S.: Trends in U.S. wage inequality: re-assessing the revisionists. Rev. Econ. Stat. 90(2), 300-323 (2008)

6. Betts, J., Roemer, J.: Equalizing opportunity for racial and socioeconomic groups in the United States through educational finance reform. In: Woessmann, L., Peterson, P. (eds.) Schools and the Equal Opportunity Problem. MIT, Cambridge (2006)

7. Bourguignon, F., Ferreira, F.H., Lustig, N. (eds.): The Microeconomics of Income Distribution Dynamics, 436 pp. World Bank, Oxford University Press, Washington, DC (2005)

8. Bourguignon, F., Ferreira, F.H., Menendez, M.: Inequality of opportunity in Brasil. Rev. Income Wealth 53(4), 585-618 (2007)

9. Buchinsky, M.: Changes in the U.S. wage structure 1963-1987: application of quantile regression. Econometrica 62(2), 405-458 (1994)

10. Cameron, S., Taber, C.: Estimation of educational borrowing constraints using returns to schooling. J. Polit. Econ. 112(1), 132-182 (2004)

11. Carneiro, P., Heckman, J.: The evidence on credit contraints in post-secondary schooling. Econ. J. 112, 989-1018 (2002)

12. Checchi, D., Peragine, V.: Regional disparities and inequality of opportunity: the case of Italy. IZA Discussion Paper No. 1874 (2005)

13. Dardanoni, V., Fields, G.S., Roemer, J., Sanchez-Puerta, M.L.: How demanding should equality of opportunity be, and how much have we achieved? In: Morgan, S., Grusky, D., Fields, G. (eds.) Mobility and Inequality: Frontiers of Reasearch in Sociology and Economics. Stanford University Press, Stanford (2005)

14. Davidson, R., Duclos, J.-Y.: Statistical inference for stochastic dominance and for the measurement of poverty and inequality. Econometrica 68(6), 1435-1464 (2000)

15. Dinardo, J., Fortin, N., Lemieux, T.: Labor market institutions and the distribution of wages, 1973-1992: a semi-parametric approach. Econometrica 64, 1001-1044 (1996)

16. Donald, S.G., Green, D.A., Paarsch, H.J.: Differences in wage distributions between Canada and the United States: an application of a flexible estimator of distribution functions in the presence of covariates. Rev. Econ. Stud. 67(4), 609-633 (2000)

17. Dworkin, R.: What is equality. part 1: equality of welfare. Philos. Public Aff. 10, 185-246 (1981)

18. Eckstein, Z., Nagypal, E.: The evolution of U.S. earnings inequality. Fed. Reserve Bank Minneap. Q. Rev. 28(2), 10-29 (2004)

19. Gottschalk, P., Danziger, S.: Inequality of wage rates, earnings and family income in the UnitedStates, 1975-2002. Rev. Income Wealth 51(2), 231-254 (2005)

20. Gottschalk, P., Joyce, M.: Cross-national differences in the rise in earnings inequality: market and institutional factors. Rev. Econ. Stat. 80(4), 489-502 (1998)

21. Gottschalk, P., Smeeding, T.M.: Cross-national comparisons of earnings and income inequality. J. Econ. Lit. 35, 663-687 (1997)

22. Jenkins, S.: Accounting for inequality trends: decomposition analyses for the U.K., 1971-86. Economica 62(1), 29-63 (1995)

23. Juhn, C., Murphy, K.M., Pierce, B.: Wage inequality and the rise in return to skill. J. Polit. Econ. 101, 410-442 (1993)

24. Katz, L.F., Autor, D.H.: Changes in the wage structure and earnings inequality. In: Ashenfelter, O., Card, D. (eds.) Handbook of Labor Economics, vol. 3A. Elsevier Science, Amsterdam (1999)

25. Katz, L.F., Murphy, K.M.: Changes in relative wages, 1963-1987: supply and demand factors. Q. J. Econ. 107, 35-78 (1992)

26. Lefranc, A., Pistolesi, N., Trannoy, A.: Inequalities of outcome vs inequalities of opportunities: are all western societies alike? Rev. Income Wealth (2005, forthcoming)

27. Lemieux, T.: Increasing residual wage inequality: composition effects, noisy data, or rising demand for skills? Am. Econ. Rev. 96, 461-498 (2006)

28. Levy, F., Murnane, R.J.: U.S. earnings levels and earnings inequality: a review of recent trends and proposed explanations. J. Econ. Lit. 30, 1333-1381 (1992) 
29. Mata, J., Machado, J.A.: Couterfactual decomposition of changes in wage distributions using quantile regression. J. Appl. Econ. 20(4), 445-465 (2005)

30. Meyer, B.D.: Unemployment insurance and unemployment spells. Econometrica 58(4), 757-782 (1990)

31. Neal, D.: Why has black-white skill convergence stopped? In: Hanushek, E., Welsh, F. (eds.) Handbook of the Economics of Education. Elsevier Science, Amsterdam (2006)

32. O'Neill, D., Sweetman, O., Van de Gaer, D.: The effect of measurement error and omitted variables when using transition matrices to measure intergenerational mobility. J. Econ. Inequal. 5(2), 159-178 (2007)

33. Roemer, J.: A pragmatic theory of responsibility for the egalitarian planner. Philos. Public Aff. 22(2), 146-166 (1993)

34. Roemer, J.: Equality of Opportunity. Harvard University Press, Cambridge (1998)

35. Van De Gaer, D.: Equality of Opportunity and Investment in Human Capital. Ph.D. thesis, K.U. Leuven (1993) 